\title{
Teknik Data Mining dalam Mengelompokkan Produktivitas Padi Menurut Provinsi Menggunakan K-Medoids
}

\author{
Safitri Ani Ritonga1 ${ }^{1}$, M Safii ${ }^{2}$, Iin Parlina ${ }^{3}$, Heru Satria Tambunan ${ }^{4}$, Susiani $^{5}$ \\ 1,2,3Program Studi Sistem Informasi, STIKOM Tunas Bangsa Pematangsiantar \\ Jln. Jendral Sudirman Blok A No. 1,2,3 Pematangsiantar \\ safitrianiritonga1@gmail.com
}

\begin{abstract}
Rice is a staple food raw material that is vital for the people, and one of the leading commodities that is cultivated by most farmers, making it an indicator of the Indonesian economy. Where the price of rice is a reflection of a country's ability to manage its economy. Rice productivity is decreasing because there are many obstacles faced by farmers such as superior seeds, fertilizers, pest eradication drugs, plant diseases, and labor in the agricultural sector. This study proposes the use of the K-Medoids method to determine the high and low productivity of rice in the province. The research results obtained were Cluster 1 (low) $=17$ provinces, Cluster 2 (moderate) $=7$ Provinces, and Cluster $3($ High $)=10$ Provinces.
\end{abstract}

Keyword : Data mining, $K$ - Medoids, Rice Productivity

Abstrak-Padi merupakan bahan baku pangan pokok yang vital bagi rakyat, dan salah satu komoditas unggulan yang dibudidayakan oleh sebagian besar petani sehingga menjadi indikator perekonomian Indonesia. Dimana harga beras menjadi cerminan kemampuan suatu negara dalam mengelola ekonominya. Produktivitas padi menurun dikarenakan banyak sekali kendala yang dihadapi oleh petani seperti benih unggul, pupuk, obat-obatan penberantas hama, penyakit tanaman, dan tenaga kerja di sector pertanian. Penelitian ini mengusulkan penggunaan metode K-Medoids adalah untuk mengetahui tinggi rendahnya produktivitas padi di provinsi. Hasil penelitian yang diperoleh adalah Kluster 1 (rendah) = 17 provinsi, Kluster 2 (sedang) $=7$ Provinsi, dan Kluster 3 (Tinggi) = 10 Provinsi.

Kata kunci: Data Mining, K-medoids, Produktivitas Padi

\section{PENDAHULUAN}

Padi merupakan bahan baku pangan pokok yang vital bagi rakyat, dan salah satu komoditas unggulan yang dibudidayakan oleh sebagian besar petani sehingga menjadi indikator perekonomian Indonesia. Menanam padi sudah mendarah daging bagi sebagian besar petani. Dimana harga beras menjadi cerminan kemampuan suatu negara dalam mengelola ekonominya. Kondisi ini memiliki kaitan yang erat dengan manajemen produksi padi yang berpengaruh terhadap pengelolaan konsumsi dan memiliki multiplier efek terhadap sektor lain. Karena padi adalah komoditas yang memiliki persoalan spesifik pada lingkungan yang spesifik maka dibutuhkan identifikasi masalah produktifitas padi dilapangan. Produktivitas padi menurun dikarenakan banyak sekali kendala yang dihadapi oleh petani seperti benih unggul, pupuk, obat-obatan penberantas hama, penyakit tanaman, dan tenaga kerja di sector pertanian. Tidak semua provinsi di Indonesia mempunyai produktivitas padi yang sama, sehingga perlu dilakukan 
pengelompokkan untuk mengetahui provinsi mana yang mempunyai produktivitas yang tinggi, sedang dan rendah, supaya produksi padi harus terus dilakukan untuk meningkatkan pendapatan dan kesejahteraan petani serta menjamin ketahanan pangan. Maka produktivitas padi harus selalu ditingkatkan agar kebutuhan masyarakat terpenuhi. Untuk itu dibutuhkan strategi yang efektif untuk mencapai tujuan yang diinginkan.

Pada penelitian ini, penulis akan membuat penelitian dalam mengelompokkan produktivitas padi di indonesia dengan metode K-Medoids. Adapun data yang digunakan dalam penelitian ini bersumber dari Badan Pusat Statistik (BPS). Dimana data yang diperoleh adalah data presentase produktivitas padi di indonesia dari tahun 2013 - 2015 yang menjelaskan bahwa produktivitas padi di indonesia menurun setiap tahunnya, seperti pada gambar 1.

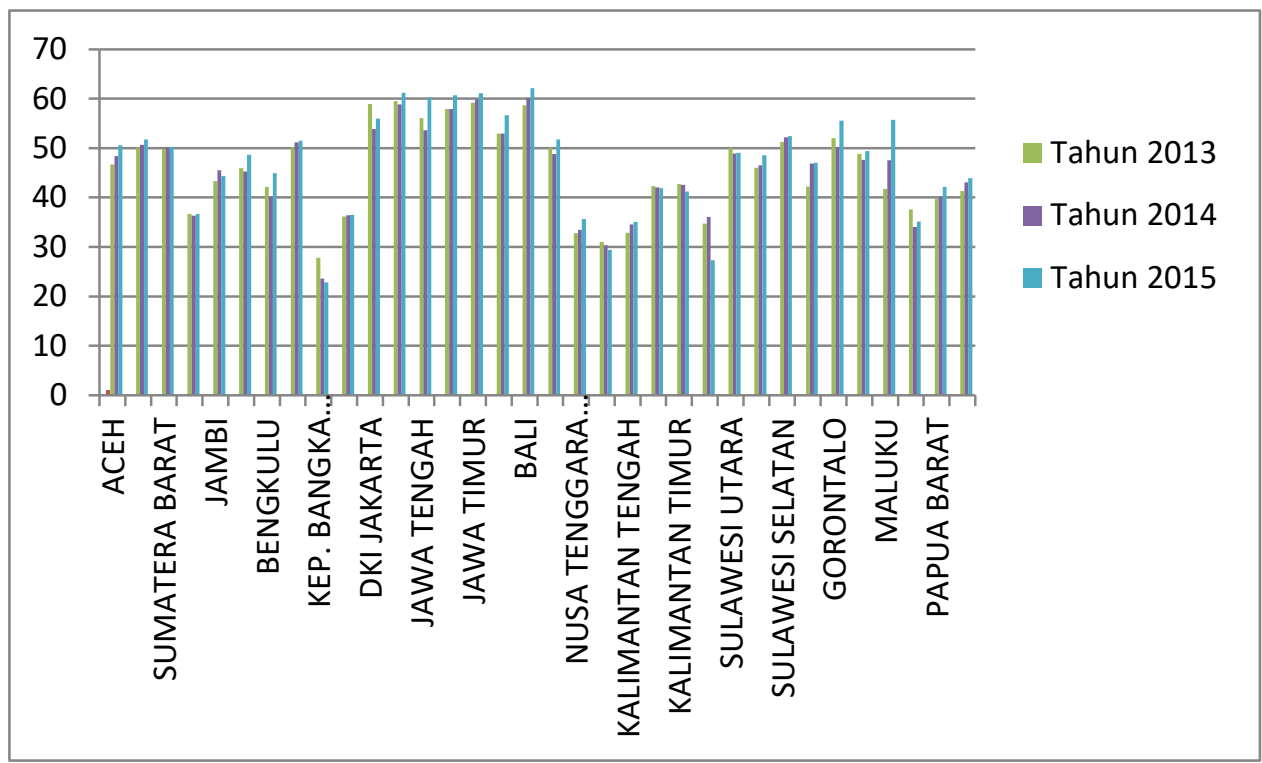

Gambar 1. Persentase Produktivitas Padi di Indonesia (Sumber : bps.go.id)

Data mining juga bisa diartikan sebagai rangkaian kegiatan untuk menemukan pola yang menarik dari data dalam jumlah yang besar, kemudian data - data tersebut dapat disimpan di database, data warehouse atau penyimpanan informasi. Ada beberapa ilmu yang mendukung teknik data mining yaitu data analisis, signal processing, neural network dan pengenalan pola [1]. Ilmu data mining mencakup banyak aspek diantaranya clustering. Algoritma kmedoids adalah salah satu algoritma clustering yang terkait dengan algoritma kmeans dengan menggunakan objek pada kumpulan objek untuk mewakili sebuah cluster [2]-[5]. Metode K-Medoids cukup efisien untuk dataset yang kecil. Kmedoids dan k-means bersifat partisional (memecah dataset kedalam beberapa kelompok) dan keduanya bertujuan untuk meminimalkan jarak antara titik yang ada dalam kluster dengan titik yang menjadi titik tengah dari kluster [6]. Beberapa penelitian terdahulu adalah [7] algoritma k-medoids untuk penentuan strategi pemasaran produk 2015, dimana data yang diambil di Swalayan menghasilkan 
lima cluster yang memiliki kombinasi jumlah barang yang dibeli paling tinggi. Dan penelitian selanjutnya yang menjelaskan algoritma paralel K-Medoids terbukti dapat meningkatkan performa proses clustering hingga mencapai 364 kali lebih cepat dibanding algoritma sekuensial K-Medoids [8]. Dalam hal ini penulis menggunakan algoritma K-Medoids dengan tools Rapidminer dalam mengelompokkan produktivitas padi menurut $\mathrm{p}$ rovinsi. Berdasarkan latar belakang masalah di atas, hasil dari cluster dapat dijadikan masukan bagi pemerintah agar meningkatkan produktivitas padi di provinsi yang memiliki cluster rendah. Proses cluster dibagi kedalam 3 (tiga) cluster yakni produktivitas padi tinggi, produktivitas padi sedang dan produktivitas padi rendah.

\section{METODOLOGI PENELITIAN}

\subsection{Analisa Data}

Dalam melakukan penelitian ini, analisis data yang digunakan adalah data kuantitatif dengan teknik analisis data yang menggunakan jenis statistic deskriptif. Penelitian ini dilakukan di STIKOM Tunas Bangsa Pematangsiantar, Jl. Jenderal Sudirman Blok A No 1, 2, 3 Pematangsiantar. Data penelitian diperoleh dengan melalui media perantara atau secara tidak langsung yang berupa buku, catatan, atau arsip baik yag dipublikasikan maupun tidak dipublikasikan secara umum. Data yang terkumpul selanjutnya diolah menggunakan algoritma $k$-medoids. Kemudian diuji dengan tools RapidMiner mennggunakan Performance yang berfungsi sebagai validasi dan reabilitas data untuk mencari keakuratan data. Data penelitian diperoleh dari Badan Pusat Statistik Nasional dengan situs https://www.bps.go.id. Data yang digunakan dalam penelitian ini adalah data persentase produktivitas padi dari tahun 2013 - 2015 yang terdiri dari 34 provinsi. Variabel yang digunakan ialah persentase produktivias padi yang sudah diakumulasikan. Data akan diolah dengan melakukan clustering persentase produktivias padi berdasarkan provinsi dalam 3 cluster yakni cluster tinggi, cluster sedang dan cluster rendah. Berikut adalah data penelitian yang digunakan, dapat dilihat pada tabel 1:

Tabel 1. Data Penelitian Produktivitas Padi

\begin{tabular}{|c|l|c|c|c|}
\hline \multirow{2}{*}{ No. } & \multicolumn{2}{|c|}{ Provinsi } & \multicolumn{3}{c|}{ Persentasi Produktivitas Padi (Hektar) } \\
\cline { 3 - 5 } & & $\mathbf{2 0 1 3}$ & $\mathbf{2 0 1 4}$ & $\mathbf{2 0 1 5}$ \\
\hline 1 & Aceh & 46,68 & 48,39 & 50,56 \\
\hline 2 & Sumatera Utara & 50,17 & 50,62 & 51,74 \\
\hline 3 & Sumatera Barat & 49,82 & 50,06 & 50,25 \\
\hline 4 & Riau & 36,63 & 36,35 & 36,63 \\
\hline 5 & Jambi & 43,36 & 45,53 & 44,31 \\
\hline 6 & Sumatera Selatan & 45,96 & 45,26 & 48,67 \\
\hline 7 & Bengkulu & 42,17 & 40,20 & 44,92 \\
\hline 8 & Lampung & 50,26 & 51,18 & 51,49 \\
\hline 9 & KEP. Bangka Belitung & 27,83 & 23,62 & 22,85 \\
\hline 10 & KEP. Riau & 36,15 & 36,44 & 36,46 \\
\hline 11 & DKI Jakarta & 58,88 & 53,86 & 55,95 \\
\hline 12 & Jawa Barat & 59,53 & 58,82 & 61,22 \\
\hline 13 & Jawa Tengah & 56,06 & 53,57 & 60,25 \\
\hline
\end{tabular}




\begin{tabular}{|c|l|c|c|c|}
\hline \multirow{2}{*}{ No. } & \multicolumn{1}{|c|}{ Provinsi } & \multicolumn{3}{|c|}{ Persentasi Produktivitas Padi (Hektar) } \\
\cline { 3 - 5 } & & $\mathbf{2 0 1 3}$ & $\mathbf{2 0 1 4}$ & $\mathbf{2 0 1 5}$ \\
\hline 14 & DI Yogyakarta & 57,88 & 57,87 & 60,65 \\
\hline 15 & Jawa Timur & 59,15 & 59,81 & 61,13 \\
\hline 16 & Banten & 52,92 & 52,95 & 56,61 \\
\hline 17 & Bali & 58,66 & 60,12 & 62,14 \\
\hline 18 & Nusa Tenggara Barat & 50,08 & 48,80 & 51,71 \\
\hline 19 & Nusa Tenggara Timur & 32,80 & 33,46 & 35,61 \\
\hline 20 & Kalimantan Barat & 31,01 & 30,35 & 29,40 \\
\hline 21 & Kalimantan Tengah & 32,84 & 34,57 & 35,07 \\
\hline 22 & Kalimantan Selatan & 42,34 & 42,05 & 41,87 \\
\hline 23 & Kalimantan Timur & 42,70 & 42,55 & 41,20 \\
\hline 24 & Kalimantan Utara & 34,72 & 36,05 & 27,27 \\
\hline 25 & Sulawesi Utara & 50,10 & 48,91 & 49,05 \\
\hline 26 & Sulawesi Tengah & 45,98 & 46,54 & 48,57 \\
\hline 27 & Sulawesi Selatan & 51,22 & 52,17 & 52,41 \\
\hline 28 & Sulawesi Tenggara & 42,23 & 46,84 & 47,07 \\
\hline 29 & Gorontalo & 52,01 & 50,20 & 55,51 \\
\hline 30 & Sulawesi Barat & 48,80 & 47,65 & 49,41 \\
\hline 31 & Maluku & 41,74 & 47,52 & 55,72 \\
\hline 32 & Maluku Utara & 37,57 & 34,01 & 35,11 \\
\hline 33 & Papua Barat & 39,76 & 40,21 & 42,12 \\
\hline 34 & Papua & 41,30 & 43,09 & 43,95 \\
\hline
\end{tabular}

\subsection{Produktivitas Padi}

Padi merupakan salah satu tanaman budidaya yang terpenting dalam peradaban, sehingga menjadi indikator perekonomian Indonesia. Karena padi adalah komoditas yang memiliki persoalan spesifik pada lingkungan yang spesifik maka dibutuhkan identifikasi masalah produksi dan produktifitas padi dilapangan. Agar produksi dan produktifitas padi dapat ditingkatkan. Untuk itu dibutuhkan strategi yang sangat efektif untuk mencapai tujuan yang diinginkan [9].

\subsection{Algoritma K-Medoids}

K-Medoids Clustering, dikenal sebagai Partitioning Around Medoids (PAM), dimana varian dari metode K-Means. Hal ini didasarkan penggunaan medoids bukan dari pengamatan mean yang dimiliki oleh setiap klaster, dengan tujuan untuk mengurangi sensitivitas dari partisi sehubungan dengan nilai ekstrim yang ada di dataset [10]. Kelebihan lainnya yaitu hasil proses clustering tidak bergantung pada urutan masuk dataset [11].

Langkah-langkah K-Medoids adalah [12]:

a. Pilih poin k sebagai inisial centroid / nilai tengah (medoids) sebanyak k cluster.

b. Cari semua poin yang paling dekat dengan medoids, dengan cara menghitung jarak vektor antar dokumen dengan menggunakan Euclidean Distance. Rumusnya adalah sebagai berikut :

$$
d(x, y)=\sqrt{\sum_{i=1}^{n}|x i-y j|^{2}}
$$


Dimana:

$\mathrm{d}(\mathrm{x}, \mathrm{y})=$ jarak antara data ke-i dan data ke-j

xi1 = nilai atribut ke satu dari data ke-i

yj1 = nilai atribut ke satu dari data ke-j

$\mathrm{n}=$ jumlah atribut yang digunakan

c. Secara acak, pilih poin yang bukan medoids.

d. Hitung total jarak antar medoid.

e. Jika TD baru < TD awal, tukar posisi medoids dengan medoids baru, jadilah medoids yang baru.

Ulangi langkah 2-5 sampai medoids tidak berubah.

\section{HASIL DAN PEMBAHASAN}

\subsection{Analisa Algoritma K-Medoids}

Langkah - langkah dalam menyelesaikan perhitungan manual data mining menggunakan k-medoids clustering menggunakan 3 cluster yaitu:

a. Inisialisasi pusat cluster sebanyak 3 cluster dari data sampel. Untuk pemilihan setiap medoid dipilih secara acak. Seperti pada tabel 2. berikut:

Tabel 2. Pusat Cluster Medoid I

\begin{tabular}{|c|l|c|c|c|}
\hline No. & \multicolumn{1}{|c|}{ Provinsi } & $\mathbf{2 0 1 3}$ & $\mathbf{2 0 1 4}$ & $\mathbf{2 0 1 5}$ \\
\hline 1 & KEP. Riau (C1) & 36,15 & 36,44 & 36,46 \\
\hline 2 & Kalimantan Selatan (C2) & 42,34 & 42,05 & 41,87 \\
\hline 3 & Papua Barat (C3) & 39,76 & 40,21 & 42,12 \\
\hline
\end{tabular}

b. Menghitung nilai jarak (cost) dengan persamaan Euclidian Distance: untuk menghitung jarak antara titik centroid dengan titik tiap objek menggunakan Euclidian Distance. Rumus untuk menghitung jarak menggunakan persamaan (2). Maka perhitungan untuk jarak pada medoid ke - 1 adalah sebagai berikut: Perhitungan (C1) sebagai berikut:

$$
\begin{aligned}
\mathrm{D}(\text { Aceh }) & =\sqrt{\left(\left((46,68-36,15)^{2}+(48,39-36,44)^{2}+(50,56-36,46)^{2}\right.\right.} \\
& =21,27189225 \\
\mathrm{D}(\text { Sumut }) & =\sqrt{\left(\left((50,17-36,15)^{2}+(50,62-36,44)^{2}+(51,74-36,46)^{2}\right.\right.} \\
& =25,12192668 \\
\mathrm{D}(\text { Sumbar }) & =\sqrt{\left(\left((49,82-36,15)^{2}+(50,06-36,44)^{2}+(50,25-36,46)^{2}\right.\right.} \\
& =23,7178709 \\
\mathrm{D}(\text { Papua }) & =\sqrt{\left(\left((41,30-46,68)^{2}+(43,09-48,39)^{2}+(43,95-36,46)^{2}\right.\right.} \\
& =11,262553
\end{aligned}
$$

Tabel 3. Hasil Perhitungan

\begin{tabular}{|c|l|c|c|c|}
\hline No. & Provinsi & $\begin{array}{c}\text { Hasil Perhitungan } \\
\text { C1 }\end{array}$ & $\begin{array}{c}\text { Hasil } \\
\text { Perhitungan C2 }\end{array}$ & $\begin{array}{c}\text { Hasil Perhitungan } \\
\text { C3 }\end{array}$ \\
\hline 1 & Aceh & 21.27189225 & 11.59945257 & 13.6393695 \\
\hline 2 & Sumatera Utara & 25.12192668 & 15.23714868 & 17.5863754 \\
\hline 3 & Sumatera Barat & 23.7178709 & 13.7961915 & 16.2580134 \\
\hline
\end{tabular}




\begin{tabular}{|c|c|c|c|c|}
\hline No. & Provinsi & $\begin{array}{c}\text { Hasil Perhitungan } \\
\text { C1 }\end{array}$ & $\begin{array}{c}\text { Hasil } \\
\text { Perhitungan C2 }\end{array}$ & $\begin{array}{c}\text { Hasil Perhitungan } \\
\text { C3 }\end{array}$ \\
\hline 4 & Riau & 0.517107339 & 9.62037941 & 7.40517387 \\
\hline 5 & Jambi & 14.00837964 & 4.370858039 & 6.78664129 \\
\hline 6 & Sumatera Selatan & 17.9753331 & 8.345567686 & 10.3365855 \\
\hline 7 & Bengkulu & 11.04307928 & 3.571260282 & 3.69434703 \\
\hline 8 & Lampung & 25.34286093 & 15.4475791 & 17.8434246 \\
\hline 9 & Kep. Bangka Belitung & 20.46477217 & 30.19876488 & 28.0871127 \\
\hline 10 & Kep. Riau & 0 & 9.95270315 & 7.69938959 \\
\hline$\ldots$ & $\ldots$ & $\ldots$ & $\ldots$ & $\ldots$ \\
\hline 33 & Papua Barat & 7.699389586 & 3.178757619 & 0 \\
\hline 34 & Papua & 11.262553 & 2.547469332 & 3.74364795 \\
\hline
\end{tabular}

Hasil dari keseluruhan dapat dilihat pada tabel 4, sebagai berikut:

Tabel 4. Hasil Perhitungan Algoritma K-Medoids Iterasi ke-1

\begin{tabular}{|c|c|c|c|c|c|c|}
\hline \multirow{2}{*}{ No } & \multirow{2}{*}{ Provinsi } & \multicolumn{3}{|c|}{ Jarak ke medoids } & \multirow{2}{*}{ Terdekat } & \multirow{2}{*}{$\begin{array}{c}\text { Klaster } \\
\text { yang } \\
\text { diikuti }\end{array}$} \\
\hline & & C1 & $\mathrm{C} 2$ & C3 & & \\
\hline 1 & Aceh & 21.27189225 & 11.59945257 & 13.6393695 & 11.59945257 & 2 \\
\hline 2 & Sumatera Utara & 25.12192668 & 15.23714868 & 17.5863754 & 15.23714868 & 2 \\
\hline 3 & Sumatera Barat & 23.7178709 & 13.7961915 & 16.2580134 & 13.7961915 & 2 \\
\hline 4 & Riau & 0.517107339 & 9.62037941 & 7.40517387 & 0.517107339 & 1 \\
\hline 5 & Jambi & 14.00837964 & 4.370858039 & 6.78664129 & 4.370858039 & 2 \\
\hline 6 & Sumatera Selatan & 17.9753331 & 8.345567686 & 10.3365855 & 8.345567686 & 2 \\
\hline 7 & Bengkulu & 11.04307928 & 3.571260282 & 3.69434703 & 3.571260282 & 2 \\
\hline 8 & Lampung & 25.34286093 & 15.4475791 & 17.8434246 & 15.4475791 & 2 \\
\hline 9 & $\begin{array}{ll}\text { KEP. } & \text { Bangka } \\
\text { Belitung } & \\
\end{array}$ & 20.46477217 & 30.19876488 & 28.0871127 & 20.46477217 & 1 \\
\hline 10 & KEP. Riau & 0 & 9.95270315 & 7.69938959 & 0 & 1 \\
\hline$\ldots$ & $\ldots$ & $\ldots$ & $\ldots$ & $\ldots$ & $\ldots$ & $\ldots$ \\
\hline 33 & Papua Barat & 7.699389586 & 3.178757619 & 0 & 0 & 3 \\
\hline 34 & Papua & 11.262553 & 2.547469332 & 3.74364795 & 2.547469332 & 2 \\
\hline & Jumlah & 674.3551148 & 505.521879 & 538.643417 & & \\
\hline & Total Cost & 1718.520411 & & & & \\
\hline
\end{tabular}

Setelah didapatkan hasil jarak dari setiap objek (cost) pada iterasi pertama maka lanjut ke iterasi 2. Kandidat medoid baru (non medoid) pada iterasi ke-2 dapat dilihat pada tabel 5 berikut:

Tabel 5. Pusat Cluster Dua

\begin{tabular}{|c|l|c|c|c|}
\hline No. & \multicolumn{1}{|c|}{ Provinsi } & $\mathbf{2 0 1 3}$ & $\mathbf{2 0 1 4}$ & $\mathbf{2 0 1 5}$ \\
\hline 1 & Papua (C1) & 41,30 & 43,09 & 43,95 \\
\hline 2 & Bali (C2) & 58,66 & 60,12 & 62,14 \\
\hline 3 & Maluku (C3) & 41,74 & 47,52 & 55,72 \\
\hline
\end{tabular}

Dengan menggunakan langkah - langkah yang sama seperti sebelumnya untuk menentukan jarak ;dari setiap objek pada iterasi ke-2, dan Berikut adalah hasil perhitungan iterasi 2 
Tabel 6. Hasil perhitungan (C1)

\begin{tabular}{|c|c|c|c|c|}
\hline No & Provinsi & $\begin{array}{c}\text { Hasil Perhitungan } \\
\text { C1 }\end{array}$ & $\begin{array}{c}\text { Hasil Perhitungan } \\
\text { C2 }\end{array}$ & $\begin{array}{c}\text { Hasil } \\
\text { Perhitungan C3 }\end{array}$ \\
\hline 1 & Aceh & 10.03625926 & 20.37669502 & 7.19625597 \\
\hline 2 & Sumatera Utara & 14.00221054 & 16.44658323 & 9.82422007 \\
\hline 3 & Sumatera Barat & 12.68311082 & 17.90869342 & 10.0826038 \\
\hline 4 & Riau & 10.9917651 & 41.24431961 & 22.7004207 \\
\hline 5 & Jambi & 3.21353388 & 27.65622895 & 11.6949818 \\
\hline 6 & Sumatera Selatan & 6.978746306 & 23.73921861 & 8.5216489 \\
\hline 7 & Bengkulu & 3.170157725 & 31.06855162 & 13.0540147 \\
\hline 8 & Lampung & 14.23310577 & 16.24518698 & 10.1920999 \\
\hline 9 & KEP. Bangka Belitung & 31.71327482 & 61.85824925 & 42.9550346 \\
\hline 10 & KEP. Riau & 11.262553 & 41.55604529 & 22.9120514 \\
\hline$\ldots$ & $\ldots$ & $\ldots$ & $\ldots$ & $\ldots$ \\
\hline 33 & Papua Barat & 3.743647954 & 33.97673469 & 15.5665186 \\
\hline 34 & Papua & 0 & 30.36884259 & 12.5837753 \\
\hline
\end{tabular}

Sehingga diperoleh hasil dari keseluruhan pada tabel 7, sebagai berikut:

Tabel 7. Hasil Perhitungan Algoritma K-Medoids Iterasi ke-2

\begin{tabular}{|c|l|l|l|l|l|l|}
\hline \multirow{2}{*}{ No } & \multirow{2}{*}{ Provinsi } & \multicolumn{3}{|c|}{ Jarak ke medoids } & \multirow{2}{*}{ Terdekat } & $\begin{array}{c}\text { Klaster } \\
\text { yang } \\
\text { diikuti }\end{array}$ \\
\cline { 3 - 6 } & & & C1 & & & 3 \\
\hline 1 & Aceh & 10.03625926 & 20.37669502 & 7.196255971 & 7.196255971 & 3 \\
\hline 2 & Sumatera Utara & 14.00221054 & 16.44658323 & 9.824220071 & 9.824220071 & 3 \\
\hline 3 & Sumatera Barat & 12.68311082 & 17.90869342 & 10.08260383 & 10.08260383 & 3 \\
\hline 4 & Riau & 10.9917651 & 41.24431961 & 22.7004207 & 10.9917651 & 1 \\
\hline 5 & Jambi & 3.21353388 & 27.65622895 & 11.69498183 & 3.21353388 & 1 \\
\hline 6 & Sumatera Selatan & 6.978746306 & 23.73921861 & 8.521648901 & 6.978746306 & 1 \\
\hline 7 & Bengkulu & 3.170157725 & 31.06855162 & 13.05401471 & 3.170157725 & 1 \\
\hline 8 & Lampung & 14.23310577 & 16.24518698 & 10.19209988 & 10.19209988 & 3 \\
\hline 9 & $\begin{array}{l}\text { KEP.Bangka } \\
\text { Belitung }\end{array}$ & 31.71327482 & 61.85824925 & 42.95503463 & 31.71327482 & 1 \\
\hline 10 & KEP. Riau & 11.262553 & 41.55604529 & 22.91205141 & 11.262553 & 1 \\
\hline$\ldots$ & $\ldots$ & $\ldots$ & $\ldots$ & $\ldots$ & $\ldots$ \\
\hline 33 & Papua Barat & 3.743647954 & 33.97673469 & 15.56651856 & 3.743647954 & 1 \\
\hline 34 & Papua & 0 & 30.36884259 & 12.58377527 & 0 & 1 \\
\hline & Jumlah & 491.2841875 & 849.7796814 & 560.1813138 & & \\
\hline
\end{tabular}

\section{c. Hitung Total Simpangan (S)}

Setelah didapatkan nilai jarak antara iterasi ke-1 dan iterasi ke-2, hitung total simpangan (S) dengan mengurangkan nilai total cost baru - nilai total cost lama. Dengan ketentuan jika $S<0$, maka tuakr nilai objek dengan menentukan medoid baru.

$$
\begin{aligned}
\text { S } & =\text { Total cost baru }- \text { Total cost lama } \\
& =1901.245183-1718.520411 \\
& =182.72477
\end{aligned}
$$

\subsection{Hasil}


Untuk mendapatkan hasil berupa pengelompokkan maka pada tahap selanjutnya dapat dilakukan dengan cara pengujian menggunakan tools RapidMiner. Hasil akhir yang akan ditampilkan adalah berupa pengelompokkan dimana hasil dari pengujian data akan tampak cluster dengan masing - masing anggota, seperti. Untuk melihat provinsi - provinsi yang termasuk dalam cluster 1 , 2 atau 3 terdapat pada gambar 3 berikut:

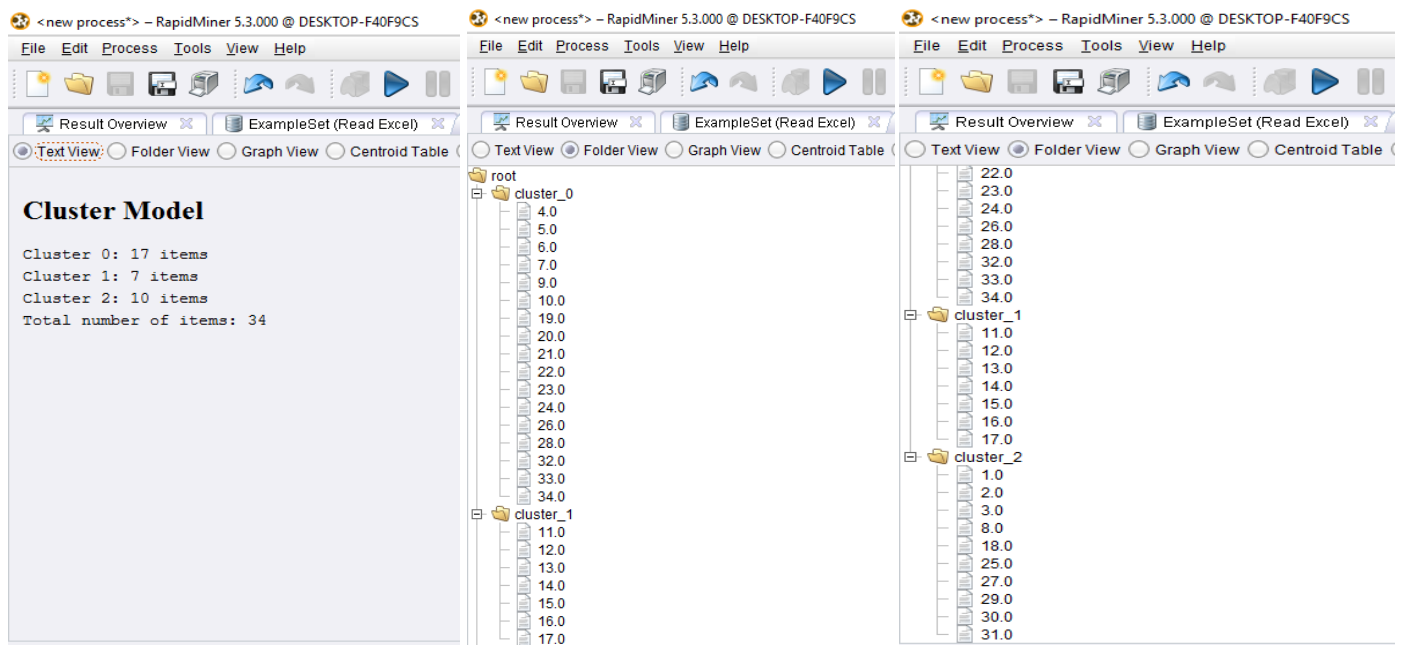

Gambar 2. Cluster Model

\subsection{Pembahasan}

Berdasarkan penjelasan diatas mengenai penggunaan serta hasil yang telah ditampilkan, keterkaitan dari hasil yang diperoleh antara perhitungan algoritma dengan hasil pengujian pada tools rapidminer 5.3. Dalam melakukan validasi data perhitungan algoritma harus menghasilkan hasil akhir berupa pengelompokkan dengan 2 cluster, serta data yang digunakan merupakan data yang valid dan sama dengan yang dipakai pada tools rapidminer 5.3. Berikut ditampilkanhasil yang didapatkan dari perhitungan algotirma dan pengujian pada rapidminer 5.3 , pada tabel 8 dibawah ini.

Tabel 8. Perbandingan Hasil Akhir K-Medoids

\begin{tabular}{|c|l|c|c|}
\hline No. & \multicolumn{1}{|c|}{ Provinsi } & $\begin{array}{c}\text { Perhitungan Algoritma K- } \\
\text { Medoids }\end{array}$ & $\begin{array}{c}\text { Pengujian Dengan } \\
\text { Rapidminer 5.3 }\end{array}$ \\
\hline 1 & Aceh & cluster_3 & cluster_2 \\
\hline 2 & Sumatera Utara & cluster_3 & cluster_2 \\
\hline 3 & Sumatera Barat & cluster_3 & cluster_2 \\
\hline 4 & Riau & cluster_1 & cluster_0 \\
\hline 5 & Jambi & cluster_1 & cluster_0 \\
\hline 6 & Sumatera Selatan & cluster_1 & cluster_0 \\
\hline 7 & Bengkulu & cluster_1 & cluster_0 \\
\hline 8 & Lampung & cluster_3 & cluster_0 \\
\hline 9 & KEP. Bangka Belitung & cluster_1 & cluster_0 \\
\hline 10 & KEP. Riau & cluster_1 & cluster_1 \\
\hline 11 & DKI Jakarta & cluster_2 & cluster_1 \\
\hline 12 & Jawa Barat & cluster_2 & \\
\hline
\end{tabular}




\begin{tabular}{|c|c|c|c|}
\hline No. & Provinsi & $\begin{array}{c}\text { Perhitungan Algoritma K- } \\
\text { Medoids }\end{array}$ & $\begin{array}{c}\text { Pengujian Dengan } \\
\text { Rapidminer } 5.3 \\
\end{array}$ \\
\hline 13 & Jawa Tengah & cluster_2 & cluster_1 \\
\hline 14 & DI Yogyakarta & cluster_2 & cluster_1 \\
\hline 15 & Jawa Timur & cluster_2 & cluster_1 \\
\hline 16 & Banten & cluster_2 & cluster_1 \\
\hline 17 & Bali & cluster_2 & cluster_1 \\
\hline 18 & Nusa Tenggara Barat & cluster_3 & cluster_2 \\
\hline 19 & Nusa Tenggara Timur & cluster_1 & cluster_0 \\
\hline 20 & Kalimantan Barat & cluster_1 & cluster_0 \\
\hline 21 & Kalimantan Tengah & cluster_1 & cluster_0 \\
\hline 22 & Kalimantan Selatan & cluster_1 & cluster_0 \\
\hline 23 & Kalimantan Timur & cluster_1 & cluster_0 \\
\hline 24 & Kalimantan Utara & cluster_1 & cluster_0 \\
\hline 25 & Sulawesi Utara & cluster_3 & cluster_2 \\
\hline 26 & Sulawesi Tengah & cluster_1 & cluster_0 \\
\hline 27 & Sulawesi Selatan & cluster_3 & cluster_2 \\
\hline 28 & Sulawesi Tenggara & cluster_1 & cluster_0 \\
\hline 29 & Gorontalo & cluster_3 & cluster_2 \\
\hline 30 & Sulawesi Barat & cluster_3 & cluster_2 \\
\hline 31 & Maluku & cluster_3 & cluster_2 \\
\hline 32 & Maluku Utara & cluster_1 & cluster_0 \\
\hline 33 & Papua Barat & cluster_1 & cluster_0 \\
\hline 34 & Papua & cluster_1 & cluster_0 \\
\hline \multicolumn{2}{|r|}{ Hasil } & $\begin{array}{l}\text { Cluster_1 (Rendah) } \\
\text { Cluster_2 (Sedang) } \\
\text { Cluster_3 (Tinggi) }\end{array}$ & $\begin{array}{c}17 \\
7 \\
10 \\
\end{array}$ \\
\hline
\end{tabular}

\section{KESIMPULAN}

Berdasarkan pembahasan sebelumnya dapat disimpulkan bahwa:

a. Penerapan Datamining dengan menggunakan algoritma K-Medoids dalam pengelompokan produktivitas padi pada cluster 1 sebanyak 17, cluster 2 sebanyak 7 dan cluster 3 sebanyak 10 .

b. Pengujian data pada Rapidminer 5.3 menggunakan K-Medoids dapat menampilkan tiga kelas dari hasil klasifikasi dengan tingkat akurasi sebesar 100 $\%$.

\section{DAFTAR PUSTAKA}

[1] A. K. Wardhani, "Implementasi Algoritma K-Means untuk Pengelompokkan Penyakit Pasien pada Puskesmas Kajen Pekalongan," Jurnal Transformatika, vol. 14, no. 1, pp. 1-8, 2016.

[2] I. Parlina, A. P. Windarto, A. Wanto, and M. R. Lubis, "Memanfaatkan Algoritma K-Means dalam Menentukan Pegawai yang Layak Mengikuti Asessment Center untuk Clustering Program SDP," CESS (Journal of Computer Engineering System and Science), vol. 3, no. 1, pp. 87-93, 2018.

[3] S. Sudirman, A. P. Windarto, and A. Wanto, "Data Mining Tools | RapidMiner: K-Means Method on Clustering of Rice Crops by Province as Efforts to Stabilize Food Crops In Indonesia," IOP Conference Series: Materials Science and Engineering, vol. 420, no. 12089, pp. 1-8, 2018.

[4] R. W. Sari, A. Wanto, and A. P. Windarto, "Implementasi Rapidminer dengan Metode K-Means (Study Kasus: Imunisasi Campak pada Balita Berdasarkan Provinsi)," KOMIK (Konferensi 
Nasional Teknologi Informasi dan Komputer), vol. 2, no. 1, pp. 224-230, 2018.

[5] M. G. Sadewo, A. P. Windarto, and A. Wanto, "Penerapan Algoritma Clustering dalam Mengelompokkan Banyaknya Desa/Kelurahan Menurut Upaya Antisipasi/ Mitigasi Bencana Alam Menurut Provinsi dengan K-Means," KOMIK (Konferensi Nasional Teknologi Informasi dan Komputer), vol. 2, no. 1, pp. 311-319, 2018.

[6] D. A. S. Simamora, M. T. Furqon, and B. Priyambadha, "Clustering Data Kejadian Tsunami Yang Disebabkan Oleh Gempa Bumi Dengan Menggunakan Algoritma K-Medoids,” vol. 1, no. 8, pp. 635-640, 2017.

[7] W. A. Triyanto, "ALGORITMA K-MEDOIDS UNTUK PENENTUAN STRATEGI PEMASARAN," vol. 6, no. 1, pp. 183-188, 2015.

[8] M. T. Furqon, A. Ridok, and W. F. Mahmudy, "Paralelisasi Algoritma K-MedoidS Pada General Purpose menggunakan Open Computing Language," Konferensi Nasional Sistem Informasi 2015, pp. 1-7, 2015.

[9] Defidelwina, A. Ariyantodan, and Y. Aini, "Strategi peningkatan produksi dan produktivitas padi sawah di kabupaten rokan hulu," Prosiding Seminar Nasional dan call for papers, vol. VII, pp. 1266-1275, 2017.

[10] Vandana Aditya Putra Sangga, "No Title," 2015.

[11] D. F. Pramesti, M. T. Furqon, and C. Dewi, "Implementasi Metode K-Medoids Clustering Untuk Pengelompokan Data Potensi Kebakaran Hutan / Lahan Berdasarkan Persebaran Titik Panas ( Hotspot )," vol. 1, no. 9, pp. 723-732, 2017.

[12] H. Zayuka, S. M. Nasution, and Y. Purwanto, "Perancangan Dan Analisis Clustering Data Menggunakan Metode K-Medoids Untuk Berita Berbahasa Inggris," e-Proceeding of Engineering : Vol.4, No.2 Agustus 2017, vol. 4, no. 2, pp. 1-9, 2017. 